\title{
Pomade Production from the Metallic Soaps of Telfairia occidentalis Seed Oil
}

\author{
Anthony P. Udoh ${ }^{1}$, Imeobong U. Udoekpo ${ }^{1}$, Edu J. Inam ${ }^{1}$ \\ ${ }^{1}$ Department of Chemistry, University of Uyo, Uyo, Akwa Ibom State, Nigeria \\ Corespondence: Anthony P. Udoh, Department of Chemistry, University of Uyo, Uyo, Akwa Ibom State, Nigeria.
}

Received: December 17, 2020 Accepted: March 16, 2021 Online Published: March 25, 2021

doi:10.5539/ijc.v13n1p30

URL: https://doi.org/10.5539/ijc.v13n1p30

\begin{abstract}
Mature fruits of Telfairia occidentalis were purchased from a local market in Ikono Local Government Area of Akwa Ibom State, Nigeria. The seeds were separated from the fleshy mesocarp, washed with water and sundried. The cotyledons were separated from the seed coat and then oven-dried at $105-110{ }^{\circ} \mathrm{C}$ for 24 hours. The dry seeds were blended into powder and the oil cold-extracted with n-hexane. The oil extracted was used to prepare copper, nickel and zinc soaps. The soaps were characterised using standard methods and then applied as additives in the production of body pomades. Several tests were performed on the control and the metallic soap pomades to establish the effectiveness of the metallic soaps in pomade production. All the prepared metallic soaps were sparingly soluble in kerosene and methanol and exhibited no foaming characteristics. The properties of the pomades imply that the metallic soaps of $T$. occidentalis have good potential in the cosmetics industry.
\end{abstract}

Keywords: pomde production, metallic soaps, seed oil, T. occidentalis

\section{Introduction}

In Nigeria, the major sources of edible oils are peanuts (Arachis hypogoea) and oil palm (Elaeis guineensis). These oils are used mainly for cooking, and for soap, margarine and cosmetics production (Ong, Choo \& Ooi, 1995). The increasing demand for oil which has led to the importation of cooking oils necessitates the need to source for other local oil bearing seeds which can be used in the commercial production of oil for both consumption and industrial applications. The majority of emollients used in personal care and beauty items are fats and oils. Oils that contain high levels of essential fatty acids such as linoleic acid are prized for their ability to replenish lipids that are found naturally within the skin layer (Harry, 2000).

In some climes, pomade is any type of cream that is robbed on the hair to make it shiny and strong. In Nigeria in particular, the word pomade is used to describe all types of body creams including that for the hair without any distinction. The product of our research was intended for use as ordinary body cream or lotion and not a hair material. Pomades are typically produced from molten wax or shea butter oil mixed with appropriate quantities of coconut oil and essential oils. In some cases, vitamin $\mathrm{E}$ is added to promote hair growth and straightening (Anon 1). Aloe vera and glycerine are also occasionally added (Anon 2). Metallic soaps are not regular ingredients in pomades or other body lotions. Metallic soaps were used in these preparations in addition to the base material (wax) to examine their effects on the quality of the prepared pomades. Testing experiments are presently ongoing.

T. occidentalis is a vegetable crop belonging to the family Cucurbitaceae. The tender stem and leaves are used as vegetable. It is an annual crop which produces fruits towards the last quarter of the year; the mature fruits are preserved for propagation but the immature fruits could be cooked and eaten just like any other edible seed. There is no time the fruits are wasted in the agricultural subsector but the increasing demand for oil for different applications necessitates sourcing for more oil to meet these demands. Although the characteristics of the seed oil of $T$. occidentalis has been presented elsewhere by a team consisting of one of us (Essien, Akpan, Etim \& Udoekpo, 2015), the use of the metallic salts of copper, zinc and nickel from the seed oil of T. occidentalis in the preparation of body pomade has not been described before and this information may be of value to the pharmaceutical industries.

\section{Materials and Methods}

\subsection{Sample Collection and Preparation}

Mature fruits of T. occidentalis were bought from a local market in Ikono Local Government Area in Akwa Ibom State of Nigeria. The seeds were manually removed from the pods and sun-dried for 48 hours, before drying in the oven for 
another 48 hours. The white cotyledons were then separated from the endocarp and oven dried at $105-110^{\circ} \mathrm{C}$ for 24 hours. The oven-dried samples were reduced into small sizes and ground into powder using a manual grinder. The powdered seeds sample was put in a large labelled container for further use. The seed oil was cold-extracted with $\mathrm{n}$-hexane and the solvent was recovered from the hexane-oil mixture as described by A.O.A.C. (1984).

\subsection{Determination of the Fatty Acid Profile of the Oil}

The fatty acid profile of the oil was determined by gas chromatography following the procedure presented by the A.O.A.C. (1984). In this procedure, a round bottom flask was washed and dried in the oven. The oil sample $(0.8 \mathrm{~g})$ was placed in it and the flask, fitted with a condenser attached to a water tap was placed on an electrothermal heater. The oil was refluxed for 3 hours using potassium hydroxide in methanol $(12 \mathrm{ml})$ to form the fatty acid methyl ester (FAME). After I hour, $\mathrm{HCl}(2 \mathrm{ml})$ was added to break the fat in the sample. At the expiration of the remaining 2 hours, heating was stopped and the flask was allowed to cool. N-hexane $(15 \mathrm{ml})$ was added to bring out all the fatty acid in the sample. Brine ( $25 \mathrm{ml}$ of $25 \%$ solution) was added to separate the fat into layers. The mixture was stirred, shaken and allowed to separate into layers and was labelled "ready for analysis". The gas chromatograph was connected to the inert gas supply. The line was evacuated for 2 minutes by turning on the vacuum pump simultaneously with the mains. A small quantity of the sample $(0.5 \mu \mathrm{l})$ was then introduced into the column through the sample port. A steady stream of the inert gas was passed through the column which was maintained at a definite temperature as directed in the user's manual. The eluent gas carried the vapourised components of the sample through the column. The recorder displayed the elution profile and the peak areas were obtained. Analyses were based on peak areas.

\subsection{Preparation of the Metallic Soaps}

The metallic soaps of copper, zinc and nickel were prepared using $\mathrm{CuSO}_{4} .5 \mathrm{H}_{2} \mathrm{O}, \mathrm{ZnSO}_{4} \cdot 7 \mathrm{H}_{2} \mathrm{O}$, and $\mathrm{NiNO}_{3} .6 \mathrm{H}_{2} \mathrm{O}$, respectively. T. occidentalis seed oil $(50 \mathrm{~g})$ was heated to $90-95^{\circ} \mathrm{C}$ in a $500 \mathrm{ml}$ beaker and sodium hydroxide solution $\left(125 \mathrm{~cm}^{3}\right.$ of $\left.10 \mathrm{M}\right)$ was added. The mixture emulsified into a thick layer during one hour of frequent stirring and was allowed to cool. The soap was separated from the lye and washed with cold distilled water to remove excess alkali. A solution of the soap $(0.05 \mathrm{M}$, based on the relative percentage of the respective fatty acid in the oil) was prepared in hot water and added with stirring to an aqueous solution of the metal salt $(0.15 \mathrm{M})$. The metallic soap which precipitated out was filtered, washed with distilled water and dried in an air ventilated oven at $40{ }^{\circ} \mathrm{C}$ for 24 hours as recommended by Ekpa and Ibok (1991).

\subsection{Characterisation of the Metallic Soaps}

The prepared metallic soaps were characterised by measuring the yield, physical appearance, moisture content, melting point, density, solubility, $\mathrm{pH}$, temperature, foaming characteristics, metal and free fatty acid contents as described in the following sections. All determinations were carried out in triplicate and average values were recorded.

\subsubsection{Determination of Yield of Metallic Soap}

The procedure as described for the preparation of metallic soaps above was used and the metallic soap which precipitated out was filtered using a pre-weighed filter paper and dried in the oven. The result was used to calculate the percentage yield using expression 1 (A.O.A.C., 1984):

$$
\text { Yield, } \%=\frac{\text { Average metallic soap precipitate } \times 100 \%}{\text { Weight of metal salt }}
$$

\subsubsection{Determination of Moisture Content}

A clean, empty beaker was heated in the oven at $105-110^{\circ} \mathrm{C}$ for 30 minutes to remove any moisture, cooled to room temperature in the desiccator and weighed. The beaker with the sample was placed in the oven for 2 hours at the stated temperature, cooled to room temperature in the desiccator and reweighed. Drying, cooling and reweighing were repeated until a constant weight was attained. The moisture content was calculated using expression 2 (A.O.A.C., 1984):

$$
\text { Moisture content }(\%)=\frac{B-C}{B-A} \times 100
$$

where $\mathrm{A}=$ weight of empty beaker, $\mathrm{B}=$ weight of beaker and sample before drying in oven, and $\mathrm{C}=$ weight of beaker and sample after drying in oven to a constant weight.

\subsubsection{Determination of Melting Point}

The solid metallic soap was picked with the open side of a one end sealed capillary tube and tapped to a length of about 1 inch. The capillary tube with the sealed side pointing down was tied to a thermometer which was clamped to a retort 
stand and inserted into a paraffin oil bath herein referred to as the melting point apparatus. Heat was applied at the bottom of the melting point apparatus while the sample was observed closely with a magnifying glass. The melting point was taken as the temperature at which the first drop of liquid was formed within the capillary tube. The determination of the melting point was carried out visually as described by A.O.A.C. (1984).

\subsubsection{Determination of Density}

The metallic soap sample $(0.3 \mathrm{~g})$ was weighed and put into $8 \mathrm{ml}$ of water in a $10 \mathrm{ml}$ measuring cylinder. The displacement of the water was read off and the density calculated using expression 3 as recommended by A.O.A.C. (1984):

$$
\text { Density }=\frac{\text { Weight of soap }}{\text { Volume of water displaced }}
$$

\subsubsection{Determination of Solubility}

The metallic soap sample (1g) was introduced into various solvents one at a time. This was stirred and observation on their solubility was made (APAG, 2010).

\subsubsection{Determination of $\mathrm{pH}$}

The sample $(0.8 \mathrm{~g})$ was weighed into a beaker, wetted with $20 \mathrm{ml}$ of ethanol by stirring with a glass rod and then $30 \mathrm{ml}$ of distilled water was added while stirring intensively. The $\mathrm{pH}$ meter was calibrated using $\mathrm{pH}$ standards 7.0 and 10.0. The $\mathrm{pH}$ was measured three times while stirring with a glass rod (allowing 2 minutes between measurements). After each measurement, the electrode was rinsed with ethanol, cleaned twice with tissue wetted with ethanol and rinsed with distilled water as recommended by A.O.A.C. (1984).

\subsubsection{Determination of Temperature}

The procedure is as described for the determination of $\mathrm{pH}$ and each time the $\mathrm{pH}$ was measured, the temperature was also measured using the same meter as recommended by A.O.A.C. (1984).

\subsubsection{Determination of Foaming Characteristics}

The metallic soap $(0.3 \mathrm{~g})$ was weighed into $8 \mathrm{ml}$ of water in a $10 \mathrm{ml}$ measuring cylinder. This was shaken vigorously and allowed to stand. The foam length was measured and the time taken for the foam to disappear was also recorded. The foaming characteristics were evaluated using these two parameters (APAG, 2010).

\subsubsection{Determination of Appearance}

Appearance is an aspect of visual experience by which things are recognised. In general terms, appearance reveals without complex mathematical, physical and chemical formulae, what kind of product a material is, how it looks, feels or smells.

\subsubsection{Determination of Colour}

This is used to describe the visual perception (at daylight) of the product. The colours of the metallic soap samples were observed visually and recorded.

\subsubsection{Determination of Texture}

The texture of the powdered solid sample was observed and recorded.

\subsubsection{Determination of Ash Content}

A crucible was washed, heated at $800{ }^{\circ} \mathrm{C}$ and cooled to room temperature in a desiccator. The crucible was weighed on an analytical balance to an accuracy of $0.1 \mathrm{mg}$. The sample $(1 \mathrm{~g})$ was placed into the crucible and reweighed. The crucible with sample was heated over a Bunsen flame, taking care to avoid any ignition or splattering until the organic matter had completely oxidised. The crucible was then put in the muffle furnace and heated to $800{ }^{\circ} \mathrm{C}$ until ashing was completed and constant weight was attained. The crucible was placed in the desiccator to cool and reweighed with the ash. The ash content was calculated using expression 4 as described by APAG (2010):

$$
\text { Ash content }(\%)=\frac{C-A}{B-C} \times 100
$$

where $\mathrm{A}$ = weight of empty crucible, $\mathrm{B}=$ weight of crucible and sample before incinerating, and $\mathrm{C}=$ weight of crucible and the residue (ash) after incinerating. 


\subsubsection{Determination of Metal Content}

The ash obtained in the above paragraph was dissolved in $5 \mathrm{ml}$ of $6 \mathrm{M} \mathrm{HCl}$ and the total volume made up to $50 \mathrm{ml}$ in a volumetric flask using distilled water. The concentration of each metal was determined with an atomic absorption spectrophotometer (Thermo Solaar Model 969) as recommended by A. O. A. C. (1984).

\subsubsection{Determination of Free Fatty Acid (FFA)}

An aliquot $(25 \mathrm{ml})$ of $95 \%$ ethanol was added to $1 \mathrm{~g}$ of the metallic soap in a conical flask and this mixture was heated to boiling in a water bath and then allowed to cool. Phenolphthalein $(1 \mathrm{ml})$ was added to the mixture in the flask and titrated with $0.1 \mathrm{M} \mathrm{NaOH}$ solution with constant shaking for proper mixing (A.O.A.C., 1984). The percentage of free fatty acid was determined using expression 5 :

$$
\% F F A=\frac{\text { Volume of } 0.1 \mathrm{M} \mathrm{NaOH} \text { used } \times 0.028 \times 100}{\text { Weight of sample }}
$$

\subsection{Preparation of Body Pomades}

For the preparation of body pomade, petroleum jelly, paraffin wax, paraffin oil, and the respective metallic soap were used. Paraffin oil $(40 \mathrm{ml})$ was poured into a clean $500 \mathrm{ml}$ beaker and heated. Paraffin wax $(0.01 \mathrm{~g})$ was added and allowed to melt and then the metallic soap $(0.1 \mathrm{~g})$ was added with vigorous stirring. Also, petroleum jelly $(40 \mathrm{~g})$ was added and allowed to melt. The beaker was then removed from the heat source and stirring was continued until the pomade thickened into an oily paste. The pomade formed was poured into a labelled container (Industrial Development Centre, FIDS, 2008). A control was also prepared with all the raw materials without a metallic soap.

\subsection{Characterisation of the Body Pomades}

\subsubsection{Determination of Moisture Content}

The moisture content of the body pomade was determined using the procedure described in the determination of moisture content of the metallic soaps.

\subsubsection{Determination of Density}

The body pomade sample was weighed into a pre-weighed container and the final weight was noted. The container with sample was put into $20 \mathrm{ml}$ of water in a $50 \mathrm{ml}$ measuring cylinder. The displacement of the water was read off and the specific gravity calculated as recommended by A.O.A.C. (1984) using expression 6:

$$
\text { Density }=\frac{\text { Weight of sample }}{\text { Equivalent volume of water displaced }}
$$

The procedure was also repeated for the control.

\subsubsection{Determination of $\mathrm{pH}$}

The $\mathrm{pH}$ of the sample was determined by melting the pomade at a temperature of $80{ }^{\circ} \mathrm{C}$ using the procedure described in the determination of the $\mathrm{pH}$ of the metallic soap.

\subsubsection{Determination of Free Fatty Acid (FFA)}

Ethanol (25ml of 95\%) was added to a known weight of the body pomade in a conical flask and this mixture was heated to boiling in a water bath and then allowed to cool. Phenolphthalein $(1 \mathrm{ml})$ was added to the mixture in the flask and titrated with $0.1 \mathrm{M} \mathrm{NaOH}$ solution with constant shaking for proper mixing. Free fatty acid was calculated as recommended by A. O. A. C. (1984) using expression 7:

$$
\% F F A=\frac{\text { Volume of } 0.1 \mathrm{M} \mathrm{NaOH} \text { used } \times 0.0282 \times 100}{\text { Weight of sample }}
$$

\subsubsection{Determination of Odour}

Smell or odour is used in general terms to describe the influence of the product on the nasal organ.

\subsubsection{Determination of Viscosity}

This was determined using the procedure described by the A. O. A. C. (1984). In this procedure, the pomade sample was drawn into the upper bulbs of a two-bulb viscometer separated by a length of capillary tubing. The time required for its meniscus to fall between calibration marks above and below the upper bulb was accurately measured. A similar measurement was made with a liquid of known viscosity (water) which served as a standard. The relative viscosity of both the sample and the standard were performed in triplicate to obtain the average. Calculation of the viscosity of the 
sample was done using the relationship in expression 8:

$$
\text { Relative viscosity }=\frac{\tau 1(\text { sample })}{\tau 2 \text { (water })}=\frac{t 1(\text { sample }) \times \ell 1(\text { sample })}{t 2(\text { water }) \times \ell 2(\text { water })}
$$

where

$\mathrm{T} 1$ (sample) $=$ Viscosity of sample,

T2 $($ water $)=$ Viscosity of water,

$\mathrm{t} 1$ (sample) $=$ Flow time of sample,

t2 $($ water $)=$ Flow time of water,

$\ell 1($ sample $)=$ Density of sample, and

$\ell 2($ water $)=$ Density of water.

\subsubsection{Determination of Fat Content}

A mixture of chloroform and methanol in the ratio of $2: 1$ was prepared and $15 \mathrm{ml}$ of the mixture was accurately measured and used for the lipid extraction. The solution of the pomade $(10 \mathrm{ml})$ was measured into a separating funnel. The chloroform-methanol mixture $(15 \mathrm{ml})$ was added to it and thoroughly shaken for about 10 minutes. This was allowed to stand for proper separation. Empty clean dry labelled beakers were weighed using an electronic balance (Mettler Toledo Ag 204). The lower layer of the separated mixture was drained into the weighed beaker and oven dried at $100-110^{\circ} \mathrm{C}$. It was then cooled for 30 minutes in a desiccator and reweighed using the same balance. The weight of the fat was obtained by the difference in weight of beakers before and after drying (A.O.A.C., 1984) and the percentage of fat calculated using expression 9:

$$
\text { Fat content }(\%)=\frac{B W_{(A D)}-B W_{(w s)} \times 100}{\text { Volume of sample used }}
$$

where $\mathrm{BW}_{(\mathrm{AD})}=$ Beaker weight after drying the sample, and $\mathrm{BW}_{(\mathrm{ws})}=$ Beaker weight without the sample.

\section{Results and Discussion}

\subsection{Fatty Acid (FA) Composition of T. occidentalis Seed Oil}

Essien et al. (2015) described the characterisation of the seed oil with respect to yield (as lipid content, $67.60 \%$ ), specific gravity $\left(0.895 \mathrm{~kg} / \mathrm{m}^{3}\right)$, refractive index (1.25), moisture content $(5.44 \%), \mathrm{pH}(4.43)$, physical appearance (as colour, light yellow), saponification value (221.80), iodine value $\left(7.11 \mathrm{gI}_{2} / 100 \mathrm{~g}\right)$, peroxide value $(1.2 \mathrm{meg} / \mathrm{kg})$, acid value $(5.49 \mathrm{mg} \mathrm{KOH} / \mathrm{g}$ oil), FFA $(2.76 \mathrm{mg} \mathrm{KOH} / \mathrm{g}$ oil), unsaponifiable matter $(0.12 \%)$ and state at room temperature (solid) using the standard procedures presented by the A.O.A.C. (1984). These were not a part of the concerns in this article.

The fatty acid composition of $T$. occidentalis seed oil is presented in Table 1 . The oil contains five main fatty acids, namely; palmitic $\left(\mathrm{C}_{16: 0}\right)$, stearic $\left(\mathrm{C}_{18: 0}\right)$, oleic $\left(\mathrm{C}_{18: 1}\right)$, linoleic $\left(\mathrm{C}_{18: 2}\right)$ and linolenic $\left(\mathrm{C}_{18: 3}\right)$ acids; the most abundant is oleic acid and the least is linolenic acid. The major saturated fatty acids in the oil are palmitic and stearic acids and the main unsaturated fatty acids are oleic and linoleic acids.

The fatty acid profile is $\mathrm{C}_{18: 1}>\mathrm{C}_{18: 2}>\mathrm{C}_{16: 0}>\mathrm{C}_{18: 0}>\mathrm{C}_{18: 3}$. The FA composition reveals that the oil is rich in polyunsaturated fatty acids (PUFA). This implies that $T$. occidentalis seed oil possesses both nutritive and medicinal properties and could be an essential source of raw materials for food and pharmaceutical industries. It is reported that PUFAs have stimulative effects on the cognitive function in mammals and are major components of the membranes neurales; they improve vision, neurotransmission and the faculty of learning in children (Anon, 1990). Therefore, consumption of the seeds of $T$. occidentalis will help to provide humans with these reported benefits. The fatty acid profile is similar to those of peanut (Ozcam, 2010) and soybean and maize (Bello, Akindele, Adeloye \& Oladimeji, 2011).

Though linolenic acid is an omega-3 fatty acid with positive health effects, it easily oxidises and is undesirable in edible oils because of the off-flavours and potentially harmful oxidation products formed (Warner \& Gupta, 2003). These authors also showed that decrease in linolenic acid from 2 to $0.8 \%$ in oils improved flavour quality and oxidative stability of fried foods. They also suggested that for an oil to be very good for frying, its linolenic acid level should be less than $1 \%$, which is the case with the seed oil of $T$. occidentalis. The low linolenic acid content makes the oil a good 
Table 1. Fatty Acid Composition of the Seed Oil of T. occidentalis in Comparison with Similar Contents in Common Vegetable Oils

\begin{tabular}{|c|c|c|c|c|c|}
\hline \multirow[b]{2}{*}{ Fatty acid } & \multicolumn{5}{|c|}{ Percentages in seed oils } \\
\hline & $\begin{array}{c}T . \\
\text { occidentalis } \\
\text { (This work) }\end{array}$ & $\begin{array}{c}\text { Peanut } \\
\text { (Ozcam, } \\
2010)\end{array}$ & $\begin{array}{c}\text { Palm olein } \\
\text { (Bello et al., } \\
\text { 2011) }\end{array}$ & $\begin{array}{l}\text { Soybean } \\
\text { (Bello et } \\
\text { al., 2011) }\end{array}$ & $\begin{array}{l}\text { Maize } \\
\text { (Bello } \\
\text { et al., } \\
\text { 2011) }\end{array}$ \\
\hline Palmitic acid & 15.37 & 9.53 & 44.00 & 11.00 & 10.50 \\
\hline Stearic acid & 11.37 & 3.14 & 4.50 & 4.00 & 2.50 \\
\hline Oleic acid & 41.08 & 52.66 & 39.20 & 22.00 & 28.00 \\
\hline Linoleic acid $\quad C_{18: 2}$ & 32.04 & 32.80 & 10.10 & 54.30 & 58.00 \\
\hline Linolenic acid $\mathrm{C}_{18: 3}$ & 0.14 & 1.88 & 0.40 & 7.50 & 1.00 \\
\hline $\begin{array}{l}\text { Total saturated } \\
\text { fatty acids }\end{array}$ & 26.74 & 9.77 & 48.50 & 15.00 & 13.00 \\
\hline $\begin{array}{l}\text { Total unsaturated } \\
\text { fatty acids }\end{array}$ & 73.26 & 87.84 & 49.70 & 83.80 & 87.00 \\
\hline
\end{tabular}

oil for the fight against cardiovascular illnesses (Boelhouwer, 1983; Achu, Fokou, Tchicgang, Fotso \& Tchouanguep, 2006). The FA composition implies that T. occidentalis seed oil can be good for table, cooking and frying oils and for the making of mayonnaise (Achu et al., 2006). The results on the fatty acid composition reveal that the oil from $T$. occidentalis seed falls in the category of high oleic oils and contains a high ratio (3:1) of unsaturated to saturated fatty acids. The results also reveal that the oil seed of $T$. occidentalis is generally a good source of crude fat.

\subsection{Characterisation of the Prepared Metallic Soaps}

The results of the characterisation of the prepared metallic soaps of copper, nickel and zinc are presented in Table 2. The colours of the metallic soaps are characteristic of the metal in the soap. All the soaps possess a powdery texture which compares favourably with the report by Kirk-Othmer (1985). The $\mathrm{pH}$ ranges of the metallic soaps imply that all are within the low acidic range. The moisture contents are low except that of the nickel soap. The low soap ash contents are an indication of high organic residue. Copper and zinc metallic soaps have densities that are lower than 1.00 while nickel soap is denser than water. The melting points of the soaps are comparable with the values obtained by Kirk-Othmer (1985) for $\mathrm{Cu}\left(112{ }^{\circ} \mathrm{C}\right), \mathrm{Ni}\left(80^{\circ} \mathrm{C}\right)$ and for $\mathrm{Zn}\left(120^{\circ} \mathrm{C}\right)$ implying that they can also be used as driers. The soaps do not exhibit any foaming characteristics and are insoluble in benzene, water and acetone but are sparingly soluble in methanol and kerosene. Essien et al. (2015) compared the properties of the soaps with similar properties for the metallic soaps from the seed oils of Citrullus lanatus and Irvingia gabonensis.

\subsection{Quality Parameters of the Pomades}

The results of the quality characteristics of the prepared body pomades using the metallic soaps as additives are presented in Table 3. The FFA content of the pomades with the metallic soap additives are much higher than that of the control which has no metallic soap additive. Reduction of fat content results in increase in FFA content of the pomades. In this case, the metals are acting as contaminants in much the same way impurities increase the boiling points of liquids. FFAs play a critical role in normal skin function and appearance (Pilkington, 2012). The oil and consequently the soaps and pomades are rich in linoleic acid which is limited in the skin. This deficiency is alleviated by the application of these metallic soaps pomades. The moisture contents in the pomades with metallic soap additives are lower than the controls without any additive. This reduction in moisture content can enhance their shelf life properties. The low fat contents make the metallic soap pomades to have advantage over other pomades and the control. All the pomades are of slightly acidic $\mathrm{pH}$. These results imply that if further refined, the $\mathrm{Zn}$-soap pomade could be used as ointment for the treatment of dandruff, the $\mathrm{Cu}$-soap pomade could be used as a fungicide spray on trees and the Ni-soap pomade could be used for water proofing leather. These properties will be further examined in our upcoming works on this seed oil. 
Table 2. Characterisation of the Metallic Soaps

\begin{tabular}{|c|c|c|c|}
\hline \multirow[t]{2}{*}{ Parameter } & \multicolumn{3}{|c|}{ Metallic soap of } \\
\hline & copper & zinc & nickel \\
\hline Yield (\%) & 43.85 & 45.50 & 49.28 \\
\hline Physical appearance (Texture) & Powdery & Powdery & Powdery \\
\hline Colour & Blue-green & White & Green \\
\hline Temperature $\left({ }^{\circ} \mathrm{C}\right)$ & 29.00 & 29.10 & 30.50 \\
\hline $\mathrm{pH}$ range & $5.18-5.20$ & $6.09-6.24$ & $6.77-6.84$ \\
\hline Moisture content (\%) & 7.80 & 13.15 & 25.28 \\
\hline Ash content $(\%)$ & 40.42 & 33.69 & 29.84 \\
\hline Density $\left(\mathrm{g} / \mathrm{cm}^{3}\right)$ & 0.60 & 0.04 & 1.50 \\
\hline Melting point range $\left({ }^{\circ} \mathrm{C}\right)$ & $100-112$ & $118-123$ & $60-88$ \\
\hline FFA & 12.41 & 22.28 & 26.51 \\
\hline Metal content $(\%)$ & 21.57 & 0.06 & 0.12 \\
\hline Foaming characteristics & None & None & None \\
\hline Solubility in: kerosene & S.S. & S.S. & S.S. \\
\hline acetone & Insoluble & Insoluble & Insoluble \\
\hline benzene & Insoluble & Insoluble & Insoluble \\
\hline methanol & S.S. & S.S. & S.S. \\
\hline water & Insoluble & Insoluble & Insoluble \\
\hline
\end{tabular}

Note: S.S. $=$ Sparingly Soluble

Table 3. Quality Parameters of the Pomades

\begin{tabular}{lcccc}
\hline Parameter & \multicolumn{4}{c}{ Pomade of: } \\
\cline { 2 - 5 } & Control & $\mathrm{Cu}$ & $\mathrm{Ni}$ & $\mathrm{Zn}$ \\
\hline Free fatty acid (\%) & 0.8 & 1.5 & 1.1 & 1.8 \\
Moisture content (\%) & 4.6 & 1.3 & 1.7 & 1.1 \\
Density & 0.7 & 0.6 & 0.6 & 0.8 \\
$\mathrm{pH}\left(\right.$ at $\left.80^{\circ} \mathrm{C}\right)$ & 6.7 & 6.8 & 6.8 & 6.6 \\
Fat content $(\%)$ & 16.2 & 6.9 & 8.9 & 16.2 \\
Odour & $\mathrm{Nil}$ & $\mathrm{Nil}$ & $\mathrm{Nil}$ & $\mathrm{Nil}$ \\
Viscosity $(\mathrm{kg} / \mathrm{m} / \mathrm{s})$ & $1.6 \times 10^{4}$ & $1.4 \times 10^{4}$ & $1.3 \times 10^{4}$ & $1.6 \times 10^{4}$ \\
\hline
\end{tabular}

\section{Conclusion}

T. occidentalis seed oil has a good blend and ratio of oleic (41.08\%) and linoleic (32.04\%) acids. The metallic soaps exhibit significant improvements in the properties of the prepared pomades in comparison with the control possibly because of the linoleic acid content. The pomades have the potential of compensating for the limited amount of linoleic acid in the skin, the usual substrate for pomade. The metallic soaps possess properties that could make them applicable as driers and have properties that if further refined, can have a wide range of industrial applications such as anti-dandruff, fungicide and water proofing depending on the metal in the soap. Therefore, T. occidentalis is a valuable crop, which seeds produce useful oil that may be an acceptable substitute for high oleic oils and which can be utilised for developing nutritionally balanced, high stability blended formulations with other high linoleic oils. The plant should be cultivated at a more commercial scale to meet these additional demands and applications.

\section{Acknowledgments}

The authors acknowledge the services of Mr. NseAbasi A. Udofia of the Central Research Laboratories, University of 
Uyo, Uyo, in taking some of the measurements.

\section{References}

A.O.A.C. (1984). Official methods of analysis of the Association of Official Analytical Chemists (14 ${ }^{\text {th }}$ Ed., Williams, S., Ed.). Washington DC, USA: AOAC Inc., pp.503-532.

Achu, M. B., Fokou, E., Tchicgang, C., Fotso, M., \& Tchouanguep, M. F. (2006). Chemical characteristics and fatty acid composition of Cucurbitaceae oils from Cameroon. https://doi.org/10.1051/IUFoST:20060026

Anon 1: http://www.onegoodthingbyjillem.com/2016/05/make-your-own-altnatural-hair-pomade.html. Accessed February 05, 2021.

Anon 2: https://www.youtube.com/watch?v=8Vnxo2A0oF0. Accessed February 05, 2021.

Anon, P. E. (1990). Health and social Wellbeing Canada: Recommendations on the Nutrition... a call to the action. Summary report/ratio of the Scientific Committee of revision and the Committee of the Communications and the Implementation. Minister for the Provisioning and Services Canada, Ottawa.

APAG. (2010). The European Oleochemicals and Allied Products Group.

Bello, M. O., Akindele, T. L., Adeloye, D. O., \& Oladimeji, A. O. (2011). Physicochemical properties and fatty acids profile of seed oil of Telferia occidentalis Hook. International Journal of Basic and Applied Sciences, IJBAS-JENS, $11(6)$.

Boelhouwer, C. (1983). Trends in chemistry and technology of lipids. Journal of American Oil Chemists'Society, 60(2), 457-462. https://doi.org/10.1007/BF02543540

Ekpa, O. D., \& Ibok, U. J. (1991). Simple methods of producing adhesives from Hevea crumb (Hevea brazilliensis). Tropical Journal of Applied Science, 1(1), 53-55.

Essien, E. A., Akpan, A. U., Etim, U. J., \& Udoekpo, I. U. (2015). Oil extraction from edible oilseeds; Irvingia gabonensis, Citrullus lanatus and Telferia occidentalis and evaluation in metallic soap preparation. International Research Journal of Pure \& Applied Chemistry, 6(2), 95-104. https://doi.org/10.9734/IRJPAC/2015/15511

Harry, R. G. (2000). Harry's cosmeticology ( $8^{\text {th }}$ Ed.). West Port: Martin M. Reiger Chemical Publishing Company, 57-58.

Industrial Development Centre FIDS. (2008). Production manual for cosmetics (Vol. 2). Abuja, Nigeria: Jack Quickgold Press, pp. 1-2.

Kirk-Othmer, P. (1985). Concise enyclopedia of chemical technology (Revised edition). New York: Macmillan Publishers, pp. 63-75.

Ong., A. S. H., Choo, Y. M., \& Ooi, C. K. (1995). Developments in palm oil. In: Hamilton, R. J. (Ed.) Developments in oils and fats. Glasgow: Blackie Academic and Professional, pp. 153-191.

https://doi.org/10.1007/978-1-4615-2183-9_6

Ozcam, M. M. (2010). Some nutritional characteristics of kernel and oil of peanut (Arachis hypogoea). Journal of Oleochemical Science, 59, 1-5. https://doi.org/10.5650/jos.59.1

Pilkington, S. (2012). Essential fatty acids and skin health. Micronutrient Information Center, Linus Pauling Institute, Oregon State University. www.http:// lpi.oregonstate.edu/mic. Retrieved February 05, 2021.

Warner, K. A., \& Gupta, M. (2003). Frying quality and stability of low and ultra low linolenic acid of soybean oils. Journal of American Oleochemists'Society, 80, 275-280. https://doi.org/10.1007/s11746-003-0689-x

\section{Copyrights}

Copyright for this article is retained by the author(s), with first publication rights granted to the journal.

This is an open-access article distributed under the terms and conditions of the Creative Commons Attribution license (http://creativecommons.org/licenses/by/4.0/). 